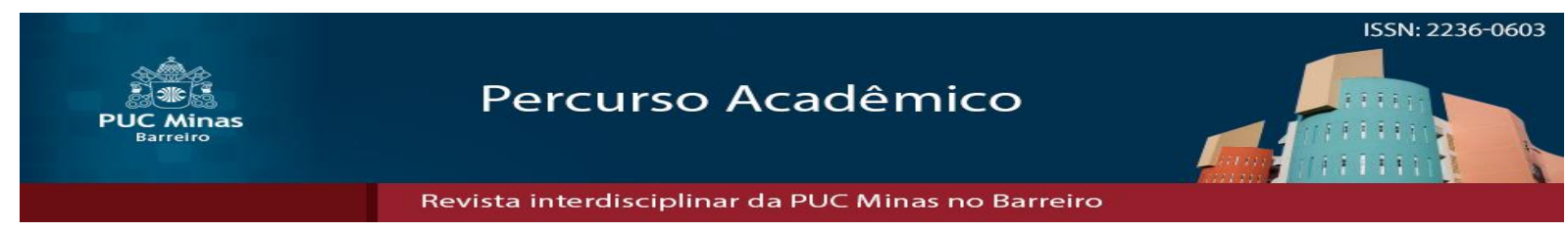

\title{
O processo de dissolução parcial de sociedade contratual regulamentado pelo CPC/2015
}

The process of partial dissolution of a contractual partnership regulated by the $\mathrm{CPC} / 2015$

Marina Grimaldi de Castro ${ }^{1}$

\section{Resumo}

Este artigo tem por objetivo a apresentar o processo de dissolução parcial de sociedade contratual regulamentado pelo $\mathrm{CPC} / 2015$ e verificar quais foram as inovações realizadas ao que já vinha sendo aplicado pelo judiciário. Para tanto, o instituto da dissolução parcial foi revisitado, expondo-se as causas que a ensejam, apontando-se algumas divergências doutrinárias existentes sobre a matéria e o atual posicionamento do STJ sobre ela. Em seguida, discorreu-se sobre o objeto da ação, a legitimidade ativa, alguns aspectos relacionados à petição inicial e à contestação, a legitimidade passiva, a data a ser considerada como a de extinção do vínculo societário com o sócio falecido, retirante ou excluído e, por fim, a forma de liquidação das quotas e os critérios utilizados para que se realize sua avaliação. Ao final do trabalho, foram feitas uma breve exposição dos principais pontos positivos da regulamentação do processo em comento e algumas observações sobre o que ainda pode ser mais bem esclarecido.

Palavras-chave: Processo. Dissolução parcial. Sociedade contratual. Liquidação de quotas. Apuração de haveres.

\begin{abstract}
The objective of this article is to present the process of partial dissolution of a contractual partnership regulated by the CPC/2015, and to verify most recent innovations made to what was already being enforced by the judiciary system. To that end, the institute of partial dissolution was revisited, exposing its purposes, the current position of the STJ on the matter, and pointing out some doctrinal divergences that exist. Furthermore, the object of the action is detailed, including the active legitimacy, some aspects related to the initial petition and the contestation, the passive legitimacy, the date to be considered as the extinction of the partnership with the deceased, retired or excluded partner and, finally, the form of settlement of the shares and the criteria used for its evaluation. To summarize the paper, a brief presentation is made of the main
\end{abstract}

\footnotetext{
Artigo recebido em 15 de Maio de 2018 e aprovado em 21 de Fevereiro de 2019

1 Doutora em Direito pela Universidade Federal de Minas Gerais (UFMG). Mestre em Direito Empresarial pela Faculdade de Direito Milton Campos. Pós-graduada no MBA Executivo Júnior em Direito da Economia e da Empresa pela Fundação Getúlio Vargas (FGV). Bacharel em Direito pela Fundação Mineira de Educação e Cultura (FUMEC). Professora de Direito Empresarial, advogada e consultora.
} 
positive points of the regulation of the process in question, and some comments on what can still be clarified.

Key-words: Process. Partial dissolution. Contractual partnership. Settlement of shares. Determination of assets.

\section{Introdução}

O instituto da dissolução parcial de sociedade contratual foi criado a partir da consolidação da teoria da preservação da empresa - e da própria sociedade -, em face da função social por ela exercida. Dessa forma, partindo-se do princípio de que a empresa deve ser conservada sempre que possível e, ainda, diante da necessidade de se equacionar os interesses da sociedade e dos sócios, a doutrina e a jurisprudência passaram a admitir a extinção do vínculo societário em relação a apenas um sócio sem que a existência da pessoa jurídica fosse interrompida. Possibilidade essa verificada devido ao fato de o contrato de sociedade ser um negócio jurídico plurilateral, permitindo com que o vínculo firmado no momento de sua celebração seja rompido somente em relação a uma das partes contratantes, mantendo-se hígido em relação às demais.

Num primeiro momento, o instituto consistia no decreto de retirada do sócio que houvesse requerido a dissolução total da sociedade, de forma a evitá-la - hipótese hoje denominada de dissolução parcial stricto sensu (FONSECA, 2005; ROSSONI, 2012; BARBOSA, 2013). Posteriormente, sua aplicação foi expandida para os demais casos em que há o rompimento do vínculo societário em relação a apenas sócio (falecimento, retirada e exclusão).

Até o advento do CPC/2015, o processo de dissolução parcial de sociedade contratual não era expressamente previsto no ordenamento jurídico. Como já vinha sendo, todavia, admitido pelo judiciário a ele se aplicava o procedimento comum. Com a entrada em vigor do novo compêndio legal, o processo passou a ser regulamentado como espécie de procedimento especial, em seu Capítulo V do Título III.

Dessa forma, diante da regulamentação do processo de dissolução parcial de sociedade contratual, torna-se relevante revisitar o instituto, verificar como ele se dá, quando há necessidade de recorrer ao judiciário para tanto e quais foram as modificações trazidas pelo CPC/2015 em relação ao que já vinha sendo aplicado pelo STJ.

Como esse objetivo, nos próximos capítulos são expostas as causas de dissolução parcial admitidas pelo Código Civil de 2002 (CC/2002) para, em seguida, tratar do procedimento especial previsto no Código de Processo Civil de 2015 (CPC/2015).

\section{As hipóteses de dissolução parcial de sociedades contratuais}

A dissolução parcial de sociedade (lato sensu) consiste na extinção do vínculo societário em relação a apenas um de seus sócios, seguida da liquidação de suas quotas e a apuração dos haveres decorrentes, por meio de balanço especial elaborado para essa finalidade (LUCENA, 2005).

Conforme disposto no CC/2002, além dos casos previstos em contrato social, o vínculo societário pode ser extinto em relação a apenas um sócio nas seguintes 
hipóteses: morte, retirada e exclusão, as quais são tratadas pormenorizadamente nas próximas subseções.

\title{
2.1 Dissolução parcial em decorrência da morte de um dos sócios
}

$\mathrm{O}$ art. 1.028 do CC/2002 determina que em caso de morte de sócio, as quotas que lhe pertenciam serão liquidadas, a menos que o contrato disponha de forma diferente, os sócios remanescentes optem por sua dissolução total, ou haja acordo com os sucessores (herdeiros e legatários) - situação em que eles ingressam na sociedade em substituição ao sócio falecido.

Dessa forma, diante da previsão contida no art. 1.028 do CC/2002, ocorrendo a morte de um dos sócios, como regra geral, as quotas que lhe pertenciam serão liquidadas e o valor correspondente será entregue aos seus sucessores.

Em contrapartida, a dissolução parcial da sociedade poderá ser evitada se os herdeiros tiverem interesse em ingressar na sociedade no lugar do sócio falecido, e os sócios remanescentes concordarem que essa substituição seja realizada. Esse entendimento entre os herdeiros do sócio falecido e os sócios remanescentes é necessário em virtude do fato de não serem os primeiros obrigados a participar da sociedade contra sua vontade, nem os sócios remanescentes de conviverem com eles, na condição de sócios, caso não haja interesse nesse sentido (por ex. ausência de affectio societatis). Conforme explica Tomazette (2014),

\begin{abstract}
[a] natureza personalista da relação entre os sócios impede que haja de pleno direito a transmissão da condição de sócio aos herdeiros do sócio falecido, pois não é indiferente para a vida da sociedade quem adquire a qualidade de sócio. [...] No caso de cláusula contratual, é óbvio que o ingresso dos herdeiros no quadro societário dependerá da manifestação deles, pois a declaração de vontade do sucedido não pode criar obrigações para eles. Trata-se de direito potestativo dos herdeiros, o ingresso na sociedade, no caso de previsão contratual (cláusula de continuidade) (TOMAZETTE, 2014, p. 322).
\end{abstract}

Dessa forma, havendo previsão no contrato social de que a sociedade não se dissolverá diante do falecimento de seus sócios, passando o vínculo que existia com ele a ser firmado com seus sucessores (cláusula de continuidade), haverá apenas necessidade deles manifestarem-se interessem em ingressar na sociedade, promovendose, consequentemente, a alteração contratual respectiva. Se eles não desejarem participar da sociedade, todavia, as quotas que lhes foram transferidas por força da herança serão liquidadas. Isso porque a vontade dos sócios previamente manifestados em contrato social não é suficiente para vincular os sucessores do falecido.

Se nada dispuser o contrato social, ainda assim, poderão os sócios remanescentes e os sucessores do falecido acordarem no sentido destes ingressarem na sociedade em substituição ao de cujus. Caso não seja essa a sua vontade, as quotas do sócio falecido serão liquidadas e seu produto entregue a quem de direito.

Por outro lado, os sócios sobreviventes possuem a prerrogativa de optar por extinguir a sociedade (dissolução total), devido à importância que o sócio falecido possuía em sua vida. Nesse caso, o vínculo societário em relação ao todos será extinto, assim como a própria sociedade.

\subsection{Dissolução parcial em decorrência do exercício do direito de retirada}


O art. 1.029 do CC/2002 atribui aos sócios de sociedades contratuais constituídas por prazo indeterminado a prerrogativa de retirar-se dela a qualquer momento, bastando sejam notificados os demais sócios com antecedência de sessenta dias. O legislador, nesse caso, parte do princípio de que ninguém é obrigado a permanecer em uma relação contratual eternamente.

Trata-se de hipótese de denúncia vazia do contrato societário, uma vez que o sócio retirante não precisa justificar as razões pelas quais exerce seu direito nem depende da ocorrência de determinados fatos para fazê-lo.

Por outro lado, o legislador confere aos sócios remanescentes o direito de dissolverem totalmente a sociedade em virtude da saída daquele que dela se retirou (parágrafo único do art. 1.029 do CC/2002), mediante deliberação aprovada por representantes da maioria do capital social (inciso III do art. 1.033 do CC/2002).

Já quando a sociedade possui prazo determinado, o sócio somente poderá dela se retirar provando judicialmente haver justa causa para tanto. O legislador não definiu, todavia, o que considera por justa causa, cabendo ao judiciário analisar se ela encontrase presente diante do caso concreto.

Há, ainda, os casos em que é atribuído aos sócios o direito de retirar-se da sociedade se não concordarem com determinadas deliberações aprovadas pela maioria. Trata-se do direito de recesso, que nada mais é do que a possibilidade de sócio o denunciar motivadamente o contrato plurilateral. Esse direito confere proteção aos minoritários ao permitir-lhes retirar-se da sociedade, mediante o reembolso de suas quotas. Ele acaba por também preservar a continuidade da sociedade, na medida em que garante aos demais sócios o direito de permanecerem vinculados entre si e de conduzirem as atividades sociais segundo suas convicções.

Esse direito é assegurado aos sócios no caso de transformação da sociedade, aprovada por deliberação da maioria, quando assim autorizado no contrato social (art. 1.114 do CC/2002). Em sociedades limitadas ele também é conferido aos sócios dissidentes de deliberações aprovadas por aqueles que representem ao menos $2 / 3$ do capital e que importem na modificação do contrato social, na fusão da sociedade com outra ou na sua incorporação por outra ou da incorporação de outra sociedade por ela (art. 1.077 do CC/2002). Essas últimas possibilidades nem precisariam ter sido previstas porque, assim como ocorre com a cisão da sociedade, implicam na modificação de seu contrato social. Vale lembrar que o legislador brasileiro não restringiu as alterações do contrato social que conferem direito de retirada ao sócio dissidente, como fez para as sociedades por ações (art. 137 da Lei n. 6.404/1976). Dessa forma, independentemente de qual seja o seu teor poderá ensejar o exercício desse direito.

O recesso é um direito potestativo conferido ao sócio dissidente, que deve exercê-lo dentro do prazo decadencial de 30 dias, contados da reunião ou assembleia de sócios que decidiu sobre uma das matérias acima colacionadas (art. 1.077 do CC/2002). Para que seja exercido e produza efeitos, basta haver notificação da sociedade nesse sentido, não sendo preciso se apresentar quaisquer justificativas ou prova de prejuízo em decorrência da modificação do contrato social aprovada pela maioria. Conforme esclarece Fonseca (2005),

[o] denominado direito de retirada representa, na verdade, muito mais do que um direito, um poder do sócio de afastar-se da sociedade sempre que discordar de qualquer modificação do contrato social. Cuida-se, na realidade, do exercício de um direito potestativo diante do qual remanesce à sociedade e aos demais sócios apenas uma posição de mera sujeição. A eficácia do referido ato subordina-se, apenas e tão-somente, à prova de que, do mesmo, à 
sociedade e aos consórcios dê o retirante o necessário conhecimento. E, do mesmo modo que não se admite contestação ou aceitação por parte da sociedade, não reclama, por parte do sócio, justificação alguma, nem tampouco sequer a comprovação de que, da alteração do contrato social tenham advindo prejuízos de qualquer natureza (FONSECA, 2005, p. 27).

A extinção do vínculo contratual, nesses casos, ocorre, portanto, por iniciativa e vontade do sócio que se retira da sociedade. Para que produza efeitos em relação a terceiros, todavia, é preciso ser realizada a alteração contratual respectiva, arquivando-a no registro público competente (art. 1.053 c.c/ parágrafo único do art. 999 do CC/2002).

Diante da previsão dos casos em que o sócio dissidente pode retirar-se da sociedade limitada, surge uma grande divergência doutrinária sobre a possibilidade ou não de se aplicar o disposto no caput do art. 1.029 do CC/2002 (denúncia vazia) a esse tipo de sociedade.

Há quem entenda (LUCENA, 2005; REQUIÃO, 2010a; TEIXEIRA, 2007) que os sócios de sociedades limitadas podem, a qualquer momento, denunciar o contrato e dela se retirar, liquidando-se suas quotas e apurando seus haveres, desde que o faça de boa-fé.

Para essa corrente doutrinária não há contradição entre o direito de retirada por denúncia vazia (art. 1.029 do CC/2002) e o direito de recesso (art. 1.077 do CC/2002), embora se reconheça que este seria exercido mais frequentemente em sociedades com prazo determinado, cuja retirada, além desse caso, somente pode ocorrer havendo justa causa comprovada judicialmente.

Por outro lado existem aqueles (COELHO, 2016; CESCHIN, 2013) que afirmam que a sociedade limitada pode ser dissolvida parcialmente em decorrência da denúncia vazia, nos termos do art. 1.029 do CC/2002, se ela for regida supletivamente pelas regras aplicáveis às sociedades simples. Se, por outro lado, houver no contrato social previsão quanto à aplicação supletiva da lei das sociedades por ações, o sócio somente pode se retirar voluntariamente da sociedade por meio do exercício de seu direito de recesso.

Por fim, há quem sustente (BORBA, 2017; BARBOSA, 2013) que o disposto no art. 1.029 da $C C / 2002$ não se aplica às sociedades limitadas, diante da previsão contida no art. 1.077 do CC/2002. Segundo Borba, a legislação subsidiária somente se aplica quando há omissão das normas específicas, o que não ocorre com as limitadas por haver expressa disposição legal quanto ao direito de retirada. Ele entende que esse sentido de permanência não conflita com o princípio que impede vinculações perpétuas, porquanto, nas limitadas "[...] o fenômeno contratual é ultrapassado pela objetivação das participações. Trata-se de investimento de capital” (BORBA, 2017, p. 155). Se o sócio pretende deixar a sociedade deve alienar suas quotas a terceiros (caso seja assim permitido) ou abandoná-las em favor da sociedade, não fazendo jus a apuração de haveres, mas ficando desobrigado das obrigações posteriormente contraídas pela sociedade da qual participava.

Barbosa (2013), por sua vez, defende que, salvo previsão contratual em sentido diverso, não se pode admitir que a

[...] dissolução parcial sirva de subterfúgio ao sócio que simplesmente se torne desgostoso ou por qualquer razão arrependido em continuar no negócio como meio de precipitar um recebimento de haveres [...] livrando o sócio retirante, por antecipação e sem qualquer oitiva ou anuência dos demais, do risco inerente ao empreendimento e pondo em xeque a continuidade destes e, 
não raro, da própria sociedade, face ao baque econômico e estrutural de surpresa postos aos demais sócios (BARBOSA, 2013, p. 369).

Apesar da divergência doutrinária cotejada, na prática a dissolução parcial de sociedades limitadas por meio de denúncia vazia - entendido como direito potestativo do sócio -, vem sido admitida reiteradamente pelo Superior Tribunal de Justiça (STJ), valendo transcrever a ementa e voto do relator de um de seus julgados:

Processo: REsp. 1602240/MG

Relator: Ministro Marco Aurélio Bellizze

Órgão julgador: Terceira Turma

Data do julgamento: 06/12/2016

Data da publicação/fonte: DJe 15/12/2016

Ementa: RECURSO ESPECIAL. AÇÃO DE DISSOLUÇÃO DE SOCIEDADE. 1. VIOLAÇÃO DOS ARTS. 535 E 538 DO CPC/1973. INEXISTÊNCIA. INDICAÇÃO DE TEMA PARA PREQUESTIONAMENTO. AUSENTE. ENUNCIADO N. 98/STJ. INAPLICABILIDADE. 2. EXERCÍCIO DO DIREITO DE RETIRADA. DIREITO POTESTATIVO. NOTIFICAÇÃO PRÉVIA E ATENDIMENTO DE PRAZO LEGAL. ART. 1.029 DO CC. DATA-BASE PARA APURAÇÃO DE HAVERES. 3. PAGAMENTO DE HAVERES. JUROS DE MORA. TERMO INICIAL. PRAZO NONGESIMAL PARA PAGAMENTO. 1.031. 4. RECURSO ESPECIAL DA EMPRESA PARCIALMENTE PROVIDO. RECURSO ESPECIAL DA SÓCIA RETIRANTE IMPROVIDO.

$[\ldots]$

Voto do relator: [...] 2. Alegação de violação do art. 1.029 do CC/2002. Data-base para apuração de haveres em dissolução parcial de empresas. Com efeito, a dissolução parcial das empresas surgiu no Brasil inicialmente pela via jurisprudencial e doutrinária, construída a partir da necessidade de se conciliar a subsistência das empresas com a livre iniciativa privada e ampla liberdade de associação. Ressalta-se que antes da vigência do atual Código Civil, a vontade de deixar o quadro societário manifestado por um dos sócios era fundamento para a dissolução total da empresa, nos termos do art. 335, 5, do Código Comercial. Posteriormente, diante de o crescente poder decisório da maioria, passou-se a contemplar, pela via legislativa, o direito de recesso do sócio dissidente como forma de proteção da minoria, nos termos do Decreto n. 3.708/1919 e das Leis de Sociedades Anônimas (Decreto-Lei n. 2.627/1940 e Lei n. 6.404/1976). Ao disciplinar o direito societário, o Código Civil de 2002 incorporou ao direito nacional o entendimento, já sedimentado jurisprudencialmente, de que o vínculo associativo não poderia ser imposto ao sócio que desejasse se retirar de sociedade constituída por prazo indeterminado, ainda que ausente a imposição de alteração contratual. Nesse rumo, excluídas as sociedades de capitais que seguem reguladas pela Lei n. 6.404/1976, o art. 1.029 do CC/2002 assegurou, de forma expressa, a possibilidade de retirada voluntária de sócios dos demais tipos societários, mediante a mera notificação da empresa, respeitado o prazo de sessenta dias de antecedência mínima. Encerrou-se assim o debate acerca das condições para a extinção do vínculo societário em relação a um sócio, agasalhando-se o direito de retirada como "mecanismo neutro, voltado para a realidade societária, que permite a cada membro, dentro do jogo de interesses internos, garantir sua liberdade de permanecer ou não associado sem recorrer à dissolução da sociedade" (SZTAJN, Rachel. O direito de recesso nas sociedades comerciais, Revista de Direito Mercantil, Industrial, Econômico e Financeiro, n. 71. Editora Revista dos Tribunais: 1988 p. 53). Tecnicamente, o direito de retirada constitui-se, portanto, em direito potestativo positivado em favor de cada sócio, individualmente considerado. Desse modo, uma vez exercido o direito e respeitado o prazo de antecedência 
da notificação, opera-se de plenamente a resilição do vínculo associativo individual, sujeitando os demais sócios e a empresa, independentemente de anuência ou de intervenção judicial.

$[\ldots]$

Acórdão: Vistos, relatados e discutidos estes autos, acordam os Ministros da Terceira Turma do Superior Tribunal de Justiça, na conformidade dos votos e das notas taquigráficas a seguir, por unanimidade, negar provimento ao recurso especial interpor por Carla Magalhães Pinto Andrade e dar parcial provimento ao recurso especial interposto por Reauto Representações de Automóveis Ltda, nos termos do voto do Sr. Ministro Relator. Os Srs. Ministros Moura Ribeiro, Nancy Andrighi, Paulo de Tarso Sanseverino e Ricardo Villas Bôas Cueva votaram com o Sr. Ministro Relator (BRASIL, 2016, grifo do autor).

Esse direito também é reconhecido pelo Departamento de Registro Empresarial e Integração (DREI), por meio do disposto no item 3.2.6.2 do Anexo II de sua Instrução Normativa $n^{\circ} 38 / 2017$.

\subsection{Dissolução parcial em decorrência da exclusão do sócio}

O CC/2002 prevê, ainda, hipóteses de exclusão do sócio de sociedade contratual, sendo que algumas delas ocorrem de pleno direito e outras por iniciativa da sociedade ou dos demais sócios. Todas elas são tratadas nas próximas subseções.

\subsubsection{Exclusão de pleno direito}

A exclusão de pleno direito é aquela que se consubstancia independentemente da vontade dos sócios e de provimento. Ela ocorre quando o sócio é declarado falido ou cujas quotas tenham sido liquidadas nos termos do parágrafo único do art. 1.026 do CC/2002 (parágrafo único do art. 1.030 do CC/2002).

O sócio declarado falido terá suas quotas liquidadas e seu produto vertido para o pagamento de seus credores no processo de execução coletiva, sendo consequentemente, excluído da sociedade, independentemente de deliberação social nesse sentido.

Corroborando o disposto no parágrafo único do art. 1.030 do CC/2002, a Lei $\mathrm{n}^{\circ}$ 11.101/2005, em seu art. 123, estabelece que se o falido fizer parte de alguma sociedade contratual ingressarão para a massa falida apenas os haveres que na sociedade ele possuir e forem apurados na forma estabelecida em contrato ou, caso omisso, judicialmente. Segundo determina o $\S 1^{\circ}$ desse mesmo artigo, a sociedade somente se dissolverá (dissolução total) se assim determinar lei especial ou constar no contrato social. Nos demais casos ocorrerá apenas a dissolução parcial.

De igual forma, será excluído da sociedade o sócio, cujo credor requerer a liquidação de suas quotas diante da insuficiência de outros bens para satisfazer sua dívida. Havendo a penhora das quotas pertencentes ao sócio de sociedade contratual, o juiz conferirá prazo à pessoa jurídica para apresentar balanço especial apurando os haveres respectivos e para que ofereça aos demais sócios a oportunidade para adquirir as referidas quotas. Não havendo interesse deles em adquirir as quotas penhoradas, a sociedade poderá fazê-lo, desde que possua reservas para tanto e não reduza o capital social. Não sendo as quotas penhoradas adquiridas pelos demais sócios ou pela sociedade, proceder-se-á, então, sua liquidação. Nesse caso, o sócio será excluído da 
sociedade e os haveres apurados serão depositados em juízo para satisfazer a obrigação contraída por ele perante seu credor (art. 861 do CPC/2015).

\subsubsection{Exclusão por iniciativa da sociedade - ou dos demais sócios}

A expulsão de um sócio por iniciativa da sociedade - ou dos demais -, em geral, se dá para dela retirar aquele que descumpra os deveres contratualmente estabelecidos ou pratique atos graves que ponham em risco sua continuidade.

Trata-se de direito conferido à sociedade para que ela possa se defender contra aqueles que colocam em risco sua existência. "É um direito inerente a finalidade comum do contrato de sociedade, independentemente de previsão contratual ou legal" (TOMAZETTE, 2014, p. 324) nesse sentido.

Conforme disposto no art. 1.030 do CC/2002, o sócio pode ser excluído judicialmente da sociedade, em decorrência do cometimento de falta grave no cumprimento de suas obrigações, mediante iniciativa da maioria dos demais.

Nas sociedades limitadas é possível haver, ainda, a exclusão extrajudicial do sócio que esteja colocando em risco sua continuidade, em virtude da prática de ato de inegável gravidade, diante da decisão tomada pela maioria dos sócios, que representem mais da metade do capital social e de alteração contratual respectiva (art. 1.085 do $\mathrm{CC} / 2002)$.

Para tanto é preciso que o contrato social preveja tal possibilidade e que a exclusão se dê por deliberação tomada em reunião ou assembleia de sócios, especialmente convocada para tanto, dando-se ciência ao acusado em tempo hábil, de forma a permitir-lhe nela comparecer e exercer seu direito de defesa (art. 1.085 do $\mathrm{CC} / 2002)$.

Ademais, a exclusão do sócio por justa causa transmite "[...] a ideia de que os motivos apontados para a exclusão do cotista minoritário precisam ser devidamente fundamentados em fatos concretos, aptos a serem comprovados num eventual litígio judicial" (CORRÊA-LIMA, 2006, p. 162).

Caso o sócio excluído discorde da deliberação tomada pela maioria dos demais sempre poderá ingressar em juízo na tentativa de anular o ato. Verifica-se, portanto, que na exclusão extrajudicial por justa causa, o legislador inverteu a ordem do procedimento usualmente adotado pelas outras sociedades contratuais e pelas limitadas que não prevejam essa possibilidade em seu contrato social. Primeiro exclui-se o sócio e depois se discute se a medida foi lícita ou não.

O sócio remisso também pode ser excluído da sociedade, mediante deliberação tomada pela maioria dos demais, caso eles não prefiram a indenização ou a redução de quotas ao montante já realizado (parágrafo único do art. 1.004 do CC/2002). Sua exclusão nessa hipótese pode ser feita extrajudicialmente, cabendo-lhe, se sentir prejudicado, contestá-la judicialmente, visando à anulação do ato (REQUIÃO, 2010b).

Caso a sociedade seja do tipo limitada, a exclusão do sócio remisso também pode ocorrer quando os demais sócios tomarem as quotas que lhe pertenciam para si ou deliberarem sobre sua transferência a terceiros, devolvendo-lhe o que houver pagado, deduzidos os juros de mora, as prestações estabelecidas no contrato social, acrescidas das despesas havidas (art. 1.058 do CC/2002).

Finalmente, o sócio pode ser excluído da sociedade em decorrência de incapacidade superveniente - fato que independe de sua culpa. Nesse caso sua exclusão se justifica pelo fato de ele não mais poder contribuir para a consecução das atividades 
sociais, além de não ser a sociedade e demais sócios obrigados a conviverem com pessoa estranha ao quadro societário - tutor ou curador do incapaz.

Apesar de a redação do caput do art. 1.030 do CC/2002 estabelecer que a exclusão do sócio que se tornou incapaz deva ser realizada judicialmente, entende-se, que ela pode ser feita extrajudicialmente caso haja previsão no contrato social nesse sentido. Por outro lado, nada impede que o contrato social contenha cláusula dispondo que a incapacidade superveniente de sócio não implicará em sua dissolução parcial exclusão do incapaz mediante a liquidação de suas quotas.

\section{0 processo de dissolução parcial de sociedade contratual}

Revistas as hipóteses de dissolução parcial de sociedade contratual contempladas pelo CC/2002, neste capítulo discorre-se sobre a respectiva ação, regulamentada pelo CPC/2015, passando por seu objeto, pessoas que possuem legitimidade ativa para sua propositura, especificidades sobre a petição inicial, legitimidade passiva e contestação, datas da resolução do vínculo societário em relação ao sócio falecido, retirante ou excluído e a forma de liquidação de suas quotas.

\subsection{O objeto da ação e as pessoas que possuem legitimidade ativa para ajuizá-la}

A ação de dissolução parcial de sociedade contratual pode ter por objeto a extinção do vínculo societário em relação ao sócio falecido, retirante ou excluído e a apuração dos haveres devidos a ele ou a seus sucessores. Pode, ainda, contemplar somente a resolução do vínculo contratual ou a apuração de haveres (art. 599 do $\mathrm{CPC} / 2015)$.

Pela leitura da primeira parte do art. 599 do CPC/2015 percebe-se que, a partir de sua vigência, o processo de dissolução parcial passa a ter duas fases distintas: a primeira, de conhecimento, por meio da qual o juiz decreta a dissolução parcial da sociedade; a segunda, na qual se apuram os haveres devidos aos sucessores do sócio falecido ou ao sócio retirante ou excluído para que, posteriormente, o pagamento respectivo lhes seja feito (SANDES; ALBERGARIA, 2012).

A possibilidade de se apurar os haveres no próprio processo que decreta ou reconhece a extinção do vínculo societário em relação a um sócio é apontada por alguns autores (YARSHELL; MATOS, 2012) como o aspecto processual mais importante trazido pela positivação e regulação da dissolução parcial como procedimento especial.

A propositura de ação de dissolução parcial que tenha como objeto exclusivamente a apuração de haveres, por outro lado, somente pode ser ajuizada nos casos em que é admitida a retirada ou exclusão extrajudicial do sócio. Afinal, para que o sócio retirante ou excluído tenha direito ao recebimento de haveres, antes, é preciso que haja o rompimento do vínculo societário.

Quando a extinção do vínculo societário deva ser decretada judicialmente, a ação de dissolução parcial poderá ter como objeto apenas a pretensão do sócio ou da sociedade - e demais sócios - em obter um provimento, de natureza constitutiva, decretando seu rompimento ou tê-la concomitantemente à pretensão de serem apurados os haveres a ele devidos em decorrência, na medida em que ninguém pode ser compelido a demandar e que os limites da demanda são definidos pelo autor (YARSHELL; MATOS, 2012).

Conforme disposto nos incisos I, II e III do caput do art. 600 do CPC/2015, em caso de dissolução parcial devido à morte de um dos sócios, a ação pode ser proposta: 
(i) pelo espólio do sócio falecido, quando a totalidade de seus sucessores não ingressar na sociedade; (ii) pelos sucessores do de cujus, depois de concluída a partilha; e (iii) pela sociedade, se os sócios sobreviventes não admitirem o ingresso dos sucessores do falecido.

Aqui é importante mencionar que pode ocorrer de o sócio falecido possuir mais de um herdeiro e/ou legatário aos quais serão atribuídas as quotas que lhes pertenciam. Nesse caso, o ingresso de cada um deles dependerá da manifestação de sua vontade nesse sentido. Pode ocorrer, portanto, que diante de um caso concreto, alguns herdeiros/legatários optem por ingressar na sociedade e outros por ter suas quotas liquidadas.

À sociedade foi atribuída, ainda, legitimidade ativa para propor a ação de dissolução parcial visando dela excluir o sócio remisso ou que aquele que comete falta grave (inciso V do art. 600 do CPC/2015).

Sandes e Albergaria (2012) apontam que no caso exclusão por falta grave, o CPC/2015 deveria ter atribuído legitimidade ativa - concorrente - para propor a ação de dissolução parcial também aos sócios remanescentes, não só porque o vínculo contratual (contrato plurilateral) estará sendo rompido para com eles - além da sociedade -, mas, ainda, porque o art. 1.030 do CC/2002 lhes confere esse direito. Mesmo entendimento se aplica à exclusão daquele que se tornou incapaz, quando o contrato social não dispuser sobre essa possibilidade.

A ação também pode ser proposta pelo sócio que houver exercido seu direito de retirada ou de recesso, caso não tenha sido providenciada pelos sócios remanescentes a alteração contratual formalizando a extinção do vínculo societário em relação a ele no prazo de 10 dias, contados do exercício de seu direito (inciso IV do caput do art. 600 do $\mathrm{CPC} / 2015$ ).

O sócio retirante pode ajuizar a ação de dissolução parcial para que seja reconhecida a extinção do vínculo societário e que ela produza efeitos perante terceiros ou, caso a sociedade tenha providenciado a averbação da alteração contratual que a formalize, para que sejam apurados e pagos os haveres a ele devidos, se não houverem sido quitados ou se houver divergência quanto à correção dos cálculos (SANDES; ALBERGARIA, 2012).

A ação pode, ainda, ser ajuizada pelo sócio que houver sido excluído ou pela sociedade, nos casos em que não se admite a exclusão extrajudicial (incisos V e VI do caput do art. 600 do CPC/2015). Na primeira hipótese a ação terá por objeto apenas a apuração de haveres, uma vez que a extinção do vínculo societário já terá ocorrido. Na segunda, a ação poderá ter por objeto somente a extinção do vínculo societário ou este cumulado com a apuração de haveres.

Finalmente, importante mencionar que o parágrafo único do art. 600 do CPC/2015 confere ao cônjuge ou companheiro, cujo casamento, união estável ou convivência terminou, legitimidade para requerer a apuração de haveres na sociedade, a ser paga a conta da liquidação das quotas daquele que possuía a condição de sócio. Tal previsão foi realizada para que o cônjuge - ou companheiro - não precise se sujeitar a providência a ser tomada pelo sócio que terá suas quotas liquidadas. Por outro lado, preserva o direito dos demais sócios em não serem obrigados a conviver com o cônjuge ou companheiro do sócio que se separou/divorciou. A dissolução parcial nesse caso ocorre de forma semelhante àquela causada pelo falecimento do sócio.

\subsection{Petição inicial, legitimidade passiva e contestação}


A petição inicial da ação de dissolução parcial de sociedade deve ser instruída, necessariamente, com seu contrato social consolidado ( $\$ 1^{\circ}$ do art. 599 do CC/2002).

Ajuizada a ação, a sociedade e seus respectivos sócios serão citados para, no prazo de 15 dias, apresentar contestação ou manifestarem sua concordância com o pedido (art. 601 do CPC/2015). O CPC/2015, positivando entendimento que já vinha sendo adotado pela jurisprudência e parte da doutrina (SANDES; ALBERGARIA, 2012), determinou que no polo passivo da ação devem ser incluídos tanto a sociedade como os sócios remanescentes, em litisconsórcio necessário. Afinal, o rompimento do vínculo societário (contrato plurilateral) gera efeitos também para os sócios remanescentes, embora seja a sociedade a responsável pelo pagamento dos haveres apurados ao sócio retirante ou excluído ou aos sucessores do sócio falecido.

Nesse sentido cita-se decisão proferida pelo STJ no AgRg no Recurso Especial $\mathrm{n}^{\circ}$ 947.545/MG:

Processo: AgRg no Recurso Especial no 947.545/MG.

Relator: Ministro Sidnei Beneti.

Órgão Julgador: Terceira Turma.

Data do julgamento: 08/02/2011.

Data da publicação/fonte: DJe 22/02/2011.

Ementa: AGRAVO REGIMENTAL. DISSOLUÇÃO PARCIAL DE SOCIEDADE COMERCIAL. OMISSÃO DO ACÓRDÃO RECORRIDO. INEXISTÊNCIA. LITISCONSÓRCIO PASSIVO NECESSÁRIO COM A SOCIEDADE COMERCIAL. AUSÊNCIA DE CITAÇÃO. NULIDADE. AUSÊNCIA DE OFENSA À COISA JULGADA. [...] II - Na ação para apuração de haveres de sócio, a legitimidade processual passiva é da sociedade empresarial e dos sócios remanescentes, em litisconsórcio passivo necessário. III - A falta de citação do litisconsorte necessário inquina de nulidade, desde a origem, o processo originário, matéria a ser apreciada, inclusive, de ofício. Em casos que tais, "os atos nulos pleno iure jamais precluem, não se sujeitando à coisa julgada, porque invalidam a formação da relação processual, podendo ser reconhecidos e declarados em qualquer época ou via." (REsp 147.769/SP, Rel. Min. SÁLVIO DE FIGUEIREDO TEIXEIRA, DJ 14.2.00) IV - Agravo Regimental improvido.

Voto do relator:

[...]

9.- Em relacão ao tema de fundo, é firme a jurisprudência deste Tribunal no sentido de que, na ação para apuração de haveres de sócio, a legitimidade processual passiva é da sociedade empresarial e dos sócios remanescentes, em litisconsórcio passivo necessário. [...]

10.- Assim, na generalidade dos casos, a retirada de sócio de sociedade por quotas de responsabilidade limitada, dá-se pela ação de dissolução parcial, com apuracão de haveres, para qual têm de ser citados não só os demais sócios, mas também a sociedade.

[...].

Acórdão: Vistos, relatados e discutidos os autos em que são partes as acima indicadas, acordam os Ministros da Terceira Turma do Superior Tribunal de Justiça, por unanimidade, negar provimento ao agravo regimental, nos termos do voto do Sr. Ministro Relator (BRASIL, 2011, grifo do autor).

Yarshell e Matos possuem, todavia, entendimento diverso. Para eles,

[...] não obstante a redação do projeto [mantida pelo CPC/2015], é que a legitimação passiva é da sociedade e não exatamente dos sócios. É do patrimônio da pessoa jurídica que deve resultar a satisfação do crédito do autor. A presença dos sócios só se justifica em dado caso concreto quando se puder imputar a eles a obrigação ou a responsabilidade patrimonial pessoal 
para a satisfação dos haveres. Fora daí, a presença dos sócios fica submetida ao critério deles próprios, que ingressarão na qualidade de assistentes (YARSHELL; MATOS, 2012, p. 231-232).

Já Rossoni defende que apenas a sociedade é parte legítima para figurar no polo passivo da ação:

\begin{abstract}
[f]ica claro que, seja para os que compreendem o objeto litigioso como a afirmação de um direito, seja para os que concebem como o pedido formulado, a relação existente entre o sócio retirante e os remanescentes não é levada a juízo. Assim, ao se definir adequadamente o objeto litigioso e, por consequência, os limites objetivos da demanda, mostra-se que não há razão que justifique a presença dos sócios, enquanto sócios, como partes no processo (ROSSONI, 2012, p. 346).
\end{abstract}

Havendo, todavia, a citação de todos os sócios, dispensa-se a citação da sociedade, que ficará sujeita aos efeitos da decisão e da coisa julgada (parágrafo único do art. 601 do CPC/2015).

Em sua contestação, a sociedade pode requerer seja o autor condenado a indenizála, sendo permitida a compensação do valor eventualmente arbitrado com o dos haveres a apurar e a pagar ao sócio ou aos seus sucessores (art. 602 do CPC/2015).

Se todos os sócios concordarem com a dissolução, o juiz a decretará e passará imediatamente a fase de liquidação das quotas do sócio falecido, retirante ou excluído (art. 603 do CPC/2015). Nesse caso, não haverá condenação de pagamento de honorários advocatícios e as custas serão rateadas entre os sócios de acordo com sua participação no capital social ( $\$ 1^{\circ}$ do art. 603 do CPC/2015).

Se não houver concordância da unanimidade dos sócios quanto à dissolução, observar-se-á o procedimento comum, devendo, todavia, serem aplicadas as regras constantes no Capítulo V do Título III do CPC/2015 para se liquidar a sentença ( $\$ 2^{\circ}$ do art. 603 do CPC/2015).

\title{
3.3 A data da extinção do vínculo contratual societário com o sócio falecido, retirante ou excluído
}

Para que sejam apurados os haveres devidos ao sócio ou a seus sucessores em caso de dissolução parcial é preciso, antes, ser fixada a data-base para a avaliação de sua participação societária, uma vez que o patrimônio da sociedade varia no tempo.

O CPC/2015 ao regulamentar o processo de dissolução parcial fixou as datas em que a extinção do vínculo do sócio falecido, retirante ou excluído com a sociedade se dá. Tal medida é salutar, pois proporciona maior segurança jurídica, considerando a divergência doutrinária e jurisprudencial existente sobre o tema, especialmente quando a dissolução parcial decorre do exercício do direito de retirada ou de exclusão por deliberação aprovada pela maioria dos demais sócios.

A divergência doutrinária sobre o momento em que ocorre a dissolução parcial em virtude do exercício do direito de retirada é exposta por Corrêa-lima (2006). Segundo ele, alguns autores entendem que a extinção do vínculo contratual não se dá desde o momento de seu exercício, mas sim com o pagamento e quitação de seus haveres. Outros afirmam que o vínculo contratual é extinto em relação ao sócio retirante a partir do momento em que ele manifesta sua vontade nesse sentido.

Barbosa (2013), por sua vez, demonstra que a divergência também ocorre entre os ministros do STJ. Uns afirmam que a extinção do vínculo ocorre com a alteração do 
contrato social ou, caso seja decretada judicialmente, com prolação de sentença. Outros entendem que o vínculo é rompido independentemente da prolação da sentença, que somente declara a dissolução parcial já ocorrida, mediante a manifestação de vontade do sócio retirante nesse sentido.

Sandes e Albergaria (2012), por sua vez, sustentam que os haveres deveriam ser apurados a partir do momento em que o sócio notifica a sociedade e não depois do transcurso do prazo de 60 dias, contados do recebimento da notificação. Isso porque nesse interregno os sócios remanescentes podem praticar uma série de atos societários que causem prejuízos ao sócio retirante.

Quanto à data em que ocorre a extinção do vínculo societário em relação ao sócio excluído, Fonseca (2005) entende que ela se dá a partir da deliberação tomada pelos demais sócios e que ela produz efeitos relativamente a terceiros tão logo seja realizado o arquivamento da alteração contratual respectiva. Corrêa-Lima (2006), por sua vez, sustenta que o vínculo societário somente estará rompido em relação ao sócio excluído depois de terem sido apurados e pagos haveres a ele devidos.

Em que pese a existência de diversos posicionamentos sobre a melhor data a ser fixada para a dissolução parcial da sociedade em virtude do exercício do direito de retirada e da exclusão extrajudicial de sócio, o legislador estabeleceu que a base de cálculo para a apuração de haveres varia conforme o fundamento que enseje a extinção do vínculo societário (art. 605 do CPC).

Havendo a dissolução parcial em virtude do falecimento do sócio, a extinção do vínculo contratual é considerada como a data de seu óbito. Exercendo o sócio o direito de retirada por denúncia vazia (art. 1.029 do CC/2002), ela ocorre a partir do sexagésimo dia seguinte ao recebimento pela pessoa jurídica da notificação encaminhada pelo primeiro. Em caso de recesso, a dissolução parcial se dá no dia em que a sociedade recebe a notificação do sócio comunicando o exercício de seu direito. Em todos esses casos a sentença proferida é de natureza declaratória e a sua eficácia se dará ex tunc (YARSHELL; MATOS, 2012). Se o sócio for excluído da sociedade extrajudicialmente, a dissolução parcial considera-se havida desde a data da reunião ou assembleia de sócios que houver deliberado sobre a matéria. Mesmo que o sócio excluído submeta o ato à apreciação do judiciário, ainda assim será aquela data a ser considerada, uma vez que a sentença confirmatória proferida nos autos possui natureza meramente declaratória.

Por fim, na retirada por justa causa de sociedade por prazo determinado e na exclusão judicial do sócio, a apuração de haveres levará em consideração a data-base do trânsito em julgado da sentença de dissolução parcial, que, diferentemente da anterior, possui natureza constitutiva, produzindo, portanto, efeitos ex nunc.

\footnotetext{
Com efeito, não se cuida de simples reconhecimento de situação preexistente - como nos casos em que a dissolução é ipso iure -, mas da constituição de um novo estado jurídico. Dessa forma, a perda da condição de sócio ocorre com o trânsito em julgado da sentença que acolhe o pedido inicial, passando o ex-sócio a ter direito de receber seus haveres (YARSHELL; MATOS, 2012, p. 234).
}

Sandes e Albergaria (2012) criticam o estabelecimento dessa data como aquela a ser considerara para apuração de haveres devidos ao sócio retirante por motivo de justa causa - a ser demonstrada em juízo -, uma vez que as ações judiciais costumam tramitar por um longo período e que nele a situação patrimonial da sociedade pode variar bastante tanto para melhor como para pior, sem falar das diversas possibilidades de os 
demais sócios praticarem atos fraudulentos para diminuir o direito patrimonial do retirante. Para eles, nesse caso, a data a ser fixada para a apuração de haveres deveria ser aquela em que o sócio manifesta sua vontade de se retirar da sociedade.

\subsection{A forma de liquidação das quotas e os critérios utilizados para que se proceda a sua avaliação}

Uma vez extinto o contrato de sociedade em relação a um de seus sócios, as quotas que lhes pertenciam serão liquidadas e seu produto (haveres) a ele entregue ou a seus sucessores. Conforme esclarecido anteriormente, para que haja a apuração dos haveres, o juiz deve fixar a data da extinção do vínculo societário de acordo com a causa que lhe deu ensejo, conforme os parâmetros estabelecidos pelo art. 605 do CPC/2015. Em seguida, deve determinar o critério a ser utilizado para sua apuração, aplicando-se o que dispuser o contrato social sobre a matéria, e nomear o perito.

Os critérios que determinam a forma de cálculo do valor correspondente aos haveres a serem pagos pela sociedade também podem variar de acordo com a causa que deu ensejo ao rompimento do vínculo societário, desde que assim esteja previsto no contrato social, uma vez que as disposições ali constantes devem, em geral, ser respeitadas pelo judiciário.

Sendo o contrato social omisso sobre o tema, o art. 1.031 do CC/2002 estabelece que as quotas pertencentes ao sócio falecido, retirante ou excluído, considerado pelo montante efetivamente integralizado, serão liquidas com base na situação patrimonial da sociedade à data da extinção de vínculo societário. Esse valor será verificado por meio de balanço especialmente levantado para essa finalidade.

Pela leitura do disposto no art. 1.031 do CC/2002 percebe-se que não foi realizada pelo legislador qualquer diferenciação entre o critério de apuração de haveres a ser adotado caso a dissolução parcial se dê por falecimento do sócio, exercício do direito de retirada ou por exclusão.

Fonseca (2005) e Barbosa (2013), apesar de tecerem uma série de críticas à ausência de diferenciação dos critérios adotados para se apurar os haveres devidos ao sócio ou a seus sucessores nos diversos casos de dissolução parcial (lato sensu), reconhecem a forte tendência apresentada pelo STJ em considerar que em todos eles deve-se avaliar o patrimônio da sociedade e, consequentemente, o valor a ser pago por ela, como se estivesse diante de sua dissolução total.

Para Fonseca (2005), somente poder-se-ia aplicar o critério de avaliação do patrimônio da sociedade como se estivesse diante de uma dissolução total para os casos de dissolução parcial stricto sensu - construção jurisprudencial que criou nova forma de afastamento do sócio que requereu a dissolução total, uma vez que a vontade unilateral do sócio não deve prevalecer sobre a função social exercida pela empresa (a ex. do disposto no inciso III do art. 1.033 e no inciso II do art. 1.034 do CC/2002). Para ela, em casos de exercício do direito de retirada, o sócio deveria receber o valor de suas quotas, apurado em balanço especial, levando-se em consideração o valor do patrimônio líquido da sociedade. Mesmo critério deveria ser utilizado para os casos em que os herdeiros do sócio falecido, embora autorizados pelos sócios remanescentes, optem por não ingressar na sociedade ou nas situações em que seu ingresso seja por eles vetado. Isso porque, nessas situações, os herdeiros nem chegariam a ser sócios da sociedade, não havendo, portanto, legitimidade ativa para requerer sua dissolução total. Já nos casos de dissolução parcial (lato sensu) em decorrência de exclusão de sócio por descumprimento de obrigação de integralizar a quota social, o reembolso devido deveria 
corresponder às importâncias por ele desembolsadas, acrescidas de juros e correção monetária.

Já, segundo o entendimento de Barbosa (2013),

[...] ao contrário do que soí ocorrer com regras processuais e procedimentais de retirada, que podem e devem ser padronizadas tanto quanto possível, no que tange à apuração de haveres e responsabilidades estas devem se dar de maneira cautelosa e, ai sim, casuística, tendo por referenciais isonomicamente sopesados: (i) as razões do desligamento; (ii) a preservação da empresa; (iii) o pagamento ao sócio daquilo com que efetivamente concorreu em prol do negócio; (iv) a vedação ao enriquecimento ilícito, máfé ou comportamento contraditório de qualquer das partes; e (v) o reconhecimento de que o sócio a priori tem direito eventual e incerto em face da sociedade que, a seu turno, além de titular o valor inerente ao estabelecimento, possui ainda toda uma gama de deveres com terceiros, que podem ser postos em risco em função da precipitação da retirada do sócio (BARBOSA, 2013, p. 389-390).

De toda forma, conforme já mencionado e reconhecido por ambos os autores, o entendimento do STJ tem sido diverso, no sentido de que deve ser adotado critério único para a apuração de haveres, independente da causa da dissolução parcial que lhe deu ensejo, destacando-se, nesse sentido, o julgamento do Recurso Especial $\mathrm{n}^{\circ}$ 1286708/PR:

\author{
Processo: REsp 1286708/PR. \\ Relatora: Ministra Nancy Andrighi. \\ Órgão Julgador: Terceira Turma. \\ Data do julgamento: 27/05/2014. \\ Data da publicação/fonte: DJe 05/06/2014. \\ Voto da Relatora:
}

[...]

33. Inicialmente, convém ressaltar que a apuração de haveres por meio de balanço de determinação, utilizada pelos tribunais nacionais, tem o escopo de apurar, à data presente, o valor patrimonial real da empresa parcialmente dissolvida. Trata-se de balanço especial destinado a apontar o valor financeiro que se alcançaria por meio da dissolução total da empresa, de forma a determinar o valor mais próximo do real a que o sócio retirante teria direito.

34. Assim, a elaboração do balanço de determinação deve atender a dois princípios, nos termos das Normas Brasileiras de Contabilidade do CFC (NBC-T-4): i) valor de mercado; e (ii) valor presente. Consectário lógico, tanto do princípio contábil do valor presente, quanto da finalidade de se apurar o valor patrimonial real da empresa e das quotas do sócio retirante, essa apuração tem por base natural a data do evento (exclusão ou retirada), de forma que alterações patrimoniais posteriores são irrelevantes para o levantamento.

35. Esse raciocínio lógico-dedutivo foi materializado no art. 1.031 do CC/02, de modo que, apesar de consistir novidade textual, já vinha sendo admitido pela jurisprudência e doutrina como decorrência da vedação ao enriquecimento sem causa. [...] (BRASIL, 2014).

Tal medida evita com que haja o injusto enriquecimento da sociedade e dos demais sócios em detrimento daquele com o qual o vínculo societário é extinto. Dessa forma, o patrimônio da sociedade deve ser avaliado pelo seu valor de mercado (FONSECA, 2005; REQUIÃO, 2010b; CORRÊA-LIMA, 2006). 
O balanço de especial - também designado como balanço de determinação - se destina a verificar a situação patrimonial da sociedade na data em que é realizado. Possui, portanto, a finalidade de "[...] permitir que se conheça a realidade patrimonial da sociedade, e não os valores que, segundo os padrões ordinários de contabilidade deveriam ser lançados" (TRINDADE; TANNNOUS, 2015, p. 499).

Em consonância com o disposto no art. 1.031 do CC/2002, o art. 606 do CPC/2015 estabelece que, em caso de omissão do contrato social, o juiz deve fixar como critério de apuração de haveres, o valor patrimonial apurado em balanço de determinação, tomando-se por referência a data da extinção do vínculo societário. Esse valor deve ser calculado levando-se em consideração os bens e direitos do ativo, tangíveis e intangíveis, a preço de saída, além do passivo, a ser apurado de igual forma.

Pela redação do art. 606 do CPC/2015 fica claro que o patrimônio da sociedade deve ser avaliado, com base na situação em que se encontrava na data da extinção do vínculo contratual com o sócio retirante, excluído ou falecido. Estabelecer que os bens e direitos integrantes do ativo, inclusive os intangíveis, devem ser avaliados pelo seu valor de saída, reforça a ideia de que, para tanto, se apura qual é o seu valor de mercado (de reposição) e não aqueles constantes nos registros contábeis da sociedade, que, em geral, são escriturados pelo seu valor de aquisição.

No balanço de determinação, além de proceder à atualização dos fatos contábeis ocorridos no período compreendido entre a data de encerramento do exercício anterior e a data de resolução da sociedade, alteram-se os critérios de avaliação e apropriação dos bens do ativo e passivo, de sorte a contabilizá-los a valor de saída ('valor de mercado') (LOPES, 2017, p. 315).

Diante do que já vinha decidindo o STJ e agora positivado expressamente no art. 606 do CPC/2015, os direitos intangíveis também devem ser considerados ao se avaliar o patrimônio da sociedade a preço de mercado. A grande questão é definir se o fundo de comércio e o goodwill devem ou não ser incluídos nessa avaliação.

[A] diferença reside em se levar em conta o valor de venda dos ativos individualmente considerados (avaliação dos ativos a preço de mercado) ou em se levar em conta a empresa como um conjunto dinâmico de bens organizados economicamente - incluindo-se, portanto, certos elementos relativos às projeções futuras como o chamado "aviamento" (avaliação econômica da empresa) (TRINDADE; TANNOUS, 2015, p. 501).

Partindo-se da premissa de que o patrimônio da sociedade deve ser avaliado com base na situação que possui na data da extinção do vínculo contratual, a perspectiva de rentabilidade não deve ser incluída nessa avaliação, uma vez que se estaria avaliando as possíveis variações patrimoniais que podem ocorrer ao longo do tempo. Afinal, admitir que os haveres devidos pela sociedade fossem avaliados levando-se em consideração sua perspectiva de rentabilidade seria o mesmo que permitir com que o sócio retirante ou excluído recebesse o valor correspondente as suas quotas antecipadamente, embora já isento dos riscos futuros inerentes à atividade, já que o vínculo contratual estará rompido (TRINDADE; TANNOUS, 2015).

Ademais, se a apuração de haveres na dissolução parcial deve ser realizada como se dissolução total fosse e considerando que esta implica na extinção da própria sociedade e que nessa ocasião o fundo de comércio também deixa de existir, seu valor não deve ser incluído na avaliação do patrimônio da sociedade para essa finalidade. 
$\mathrm{Na}$ liquidação realizada na dissolução total da sociedade, em geral, os elementos de seu ativo são alienados individualmente, distribuindo-se aos sócios a importância obtida, depois de pagos os seus credores. Dessa forma, o valor agregado ao conjunto de bens reunidos para uma finalidade específica - característica do fundo de comércio entendido como universalidade de fato - deixa de existir.

Vale dizer, ainda, que a situação do sócio que se retira ou é excluído da sociedade se aproxima da situação dos sócios de uma sociedade em liquidação, uma vez que ele reclama o reembolso de seus direitos patrimoniais existentes na data da extinção do vínculo contratual; ele não vende sua participação societária. Por tal razão, o gooowill também não deve ser considerado na avaliação do patrimônio da sociedade para fins de apuração dos haveres devidos ao sócio retirante ou excluído. Não há que se falar, nesse caso, em enriquecimento sem causa dos demais sócios e da própria sociedade, devido ao fato de não se estar diante de uma alienação de estabelecimento ou de participação societária, não havendo, portanto, a materialização do valor do goodwill (TRINDADE; TANNOUS, 2015).

\begin{abstract}
Ademais, o fato de eventualmente um goodwill (ou correlatos) "ficar" na empresa e não ser indenizado ao sócio retirante [entendimento extensível ao sócio excluído e herdeiros do sócio falecido], isso não necessariamente implica em enriquecimento - muito menos enriquecimento ilícito -, na medida em que aquele valor é inerente ao próprio estabelecimento (e, via de consequência, da empresa em seus diversos espectros), figurando os sócios retirantes ou remanescentes - na qualidade de não mais que meros credores subordinados na fila da cadeira ressarcitória, como preveem a legislação societária e falimentar em vigor (BARBOSA, 2013, p. 42).
\end{abstract}

Finalmente não se pode esquecer que o objetivo da dissolução parcial é preservar a empresa - e a própria sociedade -, de forma que o interesse particular do sócio não pode prevalecer sobre o da sociedade (FONSECA, 2005). Entende-se, portanto, que devem ser excluídos da avaliação do patrimônio da sociedade para fins de apuração de haveres em dissolução parcial, o fundo de comércio, o goodwill e outros intangíveis congêneres.

De toda forma, apurados os haveres, eles deverão ser pagos em dinheiro, no prazo de 90 dias, contados da data da liquidação das quotas, a menos que haja estipulação contratual em contrário. Essa regra será, todavia, aplicada apenas nos casos em que a dissolução parcial da sociedade ocorrer extrajudicialmente. Havendo necessidade de se recorrer ao judiciário para tanto, aplicar-se-á o disposto no art. 604 do CPC/2015.

Se houver parte incontroversa dos haveres devidos ao sócio retirante ou excluído ou aos sucessores do sócio falecido, conforme o caso, o juiz determinará a sociedade ou aos sócios remanescentes - realize em juízo o depósito do valor respectivo $\left(\S 1^{\mathrm{o}}\right.$ do art. 604 do CPC/2015). Nesse caso, o sócio retirante ou excluído ou os sucessores do sócio falecido poderão levantar desde logo o valor depositado, a menos que haja no contrato social cláusula sobre a matéria, devendo o juiz respeitar o que nele se dispôs sobre a parte incontroversa ( $\S \S 2^{\circ}$ e $3^{\circ}$ do art. 604 do CPC/2015).

Uma vez apurados os haveres do sócio retirante - falecido ou excluído -, eles serão pagos conforme disciplinar o contrato social. Não havendo previsão nesse sentido, será aplicada a regra contida no $\S 2^{\circ}$ do art. 1.031 do CC/2002, já citado (art. 609 do $\mathrm{CPC} / 2015)$.

Até o início da perícia, a data da resolução do vínculo societário e o critério de apuração dos haveres podem ser revistos pelo juiz, a pedido da parte (art. 607 do 
CPC/2015). Tal possibilidade deve ser vista com cautela, uma vez que pode gerar grande insegurança jurídica às partes envolvidas (SANDES; ALBERGARIA, 2012). Em todo caso, porém, a data da resolução deve ser aquela apontada pela lei de forma cogente (YARSHELL; MATOS, 2012). Já o critério para a apuração de haveres, como os sócios são livres para estabelecê-lo no contrato social, não há óbice para que durante o curso do processo - ou ao menos até a data designada para a realização da perícia ele seja modificado por consenso das partes ou corrigido pelo juiz, caso outro tenha sido adotado.

Finalmente, é importante lembrar que, até a data da extinção do vínculo societário, integram o valor devido ao sócio retirante ou excluído - ou aos sucessores do falecido - a participação nos lucros e os juros sobre o capital próprio, bem como sua remuneração como administrador, se for esse o caso. Após essa data, eles terão direito apenas a correção monetária do valor apurado e aos juros contratuais ou legais (art. 608 do CPC/2015).

\section{Conclusão}

Pelo estudo realizado pôde-se perceber que tanto o CC/2002 como o CPC/2015 considera haver dissolução parcial de sociedade contratual sempre que há extinção do vínculo societário em relação a apenas um de seus sócios, independentemente do motivo que lhe tenha dado causa - falecimento, retirada, exclusão ou dissolução parcial stricto sensu. De igual forma, não foi realizada qualquer diferenciação quanto aos critérios a serem adotados para a apuração de haveres conforme a causa que tenha ensejado a dissolução parcial.

Pode-se afirmar, ainda, que a regulação do processo de dissolução parcial pelo CPC/2015 se mostrou positiva ao possibilitar que num único processo se proceda a decretação ou o reconhecimento do rompimento do vínculo societário e se realize a apuração de haveres respectiva. Além disso, ela atribuiu maior segurança jurídica aos jurisdicionados, ao estabelecer as datas que devem ser consideradas ao se avaliar o patrimônio da sociedade e, consequentemente, o valor das quotas a serem liquidadas. Buscou, ainda, definir a legitimidade ativa e eliminar a controvérsia existente na doutrina sobre a legitimidade passiva daqueles que devem integrar a lide.

O legislador poderia, todavia, ter aproveitado a oportunidade para esclarecer quais intangíveis devem e quais não devem ser considerados na avaliação do patrimônio da sociedade. Afinal, pela forma como foi redigido o art. 606 do CPC/2015 ainda há margem para inclusão do fundo de comércio, goodwill e demais intangíveis congêneres nesse cálculo, o que, conforme demonstrado, não é adequado.

Apesar disso e de pequenas outras impropriedades levantadas por processualistas (não abordadas neste artigo), a regulação do processo de dissolução parcial de sociedade contratual pelo CPC/2015 foi bastante positiva, pois, embora não se tenha inovado tanto, acabou por positivar uma série de entendimentos jurisprudenciais que já vinham sendo adotados.

\section{Referências}

BARBOSA, Henrique Cunha. Dissolução parcial, recesso e exclusão de sócios: diálogos e dissensos na jurisprudência do STJ e nos projetos de CPC e Código Comercial. In: AZEVEDO, Luís N. de Moura; CASTRO, Rodrigo R. Monteiro de. (Coord.). Sociedade limitada contemporânea. São Paulo: Quartier Latin, 2013. 
BORBA, José Edwaldo Tavares. Direito societário. 15. ed. atual. e ampl. São Paulo: Atlas, 2017.

BRASIL. Código Civil (Lei $\mathrm{n}^{\circ}$ 10.406, de 10 de janeiro de 2002). Institui o Código Civil. Diário Oficial da União, Brasília, 11 jan. 2002. Disponível em: <http://www.planalto.gov.br/ccivil_03/leis/2002/110406.htm> Acesso em 11 abr. 2018.

BRASIL. Código de Processo Civil (Lei n 13.105, de 16 de março de 2015). Código de Processo Civil. Diário Oficial da União, Brasília, 17 mar. 2015. Disponível em: <http://www.planalto.gov.br/ccivil_03/_ato2015-2018/2015/lei/113105.htm> Acesso em 15 abr. 2018.

BRASIL. Lei $\mathrm{n}^{\circ} 11.101$, de 9 de fevereiro de 2005. Regula a recuperação judicial, a extrajudicial e a falência do empresário e da sociedade empresária. Diário Oficial da União, Brasília, 9 fev. 2005. Disponível em: <http://www.planalto.gov.br/ccivil_03 I_ato2004-2006/2005/lei/111101.htm> Acesso: 5 maio. 2018.

BRASIL. Lei $\mathrm{n}^{\circ}$ 6.404, de 15 de dezembro de 1976. Dispõe sobre as sociedades por ações. Diário Oficial da União, Brasília, 17 dez. 1976. Disponível em: <http://www.planalto.gov.br/ccivil_03/LEIS/L6404consol.htm> Acesso: 5 maio. 2018.

BRASIL. Superior Tribunal de Justiça. Recurso Especial $\mathrm{n}^{\circ}$ 1.602.240/MG. Recorrentes: Carla Magalhães Pinto Andrade e Reauto Representações de Automóveis. Recorridos: Os mesmos. Relator: Ministro Marco Aurélio Bellizze. Brasília, 6 de dezembro de 2016. Diário de Justiça Eletrônico, 15 dez. 2016. Disponível em: $<$ https://ww2.stj.jus.br/processo/revista/inteiroteor/?num_registro=201601234654\&dt_p ublicacao=15/12/2016> Acesso: 5 maio. 2018.

BRASIL. Superior Tribunal de Justiça. Recurso Especial $n^{\circ}$ 1286708/PR. Recorrentes: Susana Tfeli de Raad e outros. Recorridos: Os mesmos. Relatora: Ministra Nancy Andrighi. Brasília, 27 de maio de 2014. Diário de Justiça Eletrônico, 5 jun. 2014. Disponível em: <https://ww2.stj.jus.br/processo/revista/inteiroteor/?num_registro $=201102145360 \& d t \_$publicacao=05/06/2014> Acesso: 5 maio. 2018.

BRASIL. Superior Tribunal de Justiça. Agravo Regimental em Recurso Especial $\mathrm{n}^{\circ}$ 947545/MG. Agravante: Johann Alexander Merschwinsky. Agravado: Teresa Cristina Castilho Tavares da Silva. Brasília, 8 de fevereiro de 2011. . Diário de Justiça Eletrônico, 22 fev. 2011. Disponível em: <http://www.stj.jus.br/SCON/jurisprudencia $/$ doc.jsp?livre $=$ dissolucao + parcial $+e+$ litisconsorte + necessario $\& b=A C O R \& p=t r u e ~ \& l=10$ $\& \mathrm{i}=3>$ Acesso: 5 maio. 2018.

CESCHIN, Gisela. Direito de recesso na sociedade limitada e seus aspectos práticos. In: AZEVEDO, Luís N. de Moura; CASTRO, Rodrigo R. Monteiro de. (Coord.). Sociedade limitada contemporânea. São Paulo: Quartier Latin, 2013.

COELHO, Fábio. Manual de direito comercial: direito de empresa. 28. ed. São Paulo: Revista dos Tribunais, 2016. 
CORRÊA-LIMA, Osmar Brina. Sociedade limitada. Rio de Janeiro: Forense, 2006.

DEPARTAMENTO DE REGISTRO EMPRESARIAL E INTEGRAÇÃO. Instrução Normativa $n^{\circ}$ 38, de 2 de março de 2017. Institui os Manuais de Registro de Empresário Individual, Sociedade Limitada, Empresa Individual de Responsabilidade Limitada - EIRELI, Cooperativa e Sociedade Anônima. Disponível em: <http://www. mdic.gov.br/images/REPOSITORIO/SEMPE/DREI/INs_EM_VIGOR/IN-DREI-382017-retificao.pdf>. Acesso: 5 maio. 2018.

FONSECA, Priscila M. P. Corrêa da. Dissolução parcial, retirada e exclusão de sócio no novo Código Civil. 3. ed. São Paulo: Atlas, 2005.

LOPES, Marcelo Flávio Lago. A ação de dissolução parcial de sociedade no novo Código de Processo Civil: breves reflexões sobre o critério para apuração de haveres. In: BRAGA, Carlos David Albuquerque; ABDO, Helena Najjarn; FELITTE, Beatriz Valente (Coord.). Contencioso empresarial na vigência do novo Código de Processo Civil. Rio de Janeiro: Lumen Juris, 2017.

LUCENA, José Waldecy. Das sociedades limitadas. 6. ed. atual. e ampl. Rio de Janeiro: Renovar, 2005.

REQUIÃO, Rubens. Curso de direito comercial. 29. ed. São Paulo: Saraiva, 2010a. v. 1.

REQUIÃO, Rubens. Curso de direito comercial. 27. ed. São Paulo: Saraiva, 2010b. v. 2.

ROSSONI, Igor Bimkowski. O procedimento especial de dissolução parcial de sociedade no PL 166/2010 (novo Código de Processo Civil). In: YARSHELL, Flávio Luiz; PEREIRA, Guilherme Setoguti (Coord.). Processo societário. São Paulo: Quartier Latin, 2012.

SANDES, Leonardo de Almeida; ALBERGARIA, Jason Soares de. Neto. A ação de dissolução de sociedades no anteprojeto do CPC. In: SILVA, José Anchieta da. São (Org.). O novo processo civil. São Paulo: Lex, 2012.

TEIXEIRA, Egberto Lacerda. Das sociedades por quotas de responsabilidade limitada: atualizado de acordo com o novo código civil. TOZZINI, Syllas; BERGER, Renato (Atual.). 2. ed. São Paulo: Quartier Latin, 2007.

TOMAZETTE, Marlon. Curso de direito empresarial: teoria geral e direito societário. 6. ed. São Paulo: Atlas, 2014. v. 1.

TRINDADE, Marcelo Fernandez; TANNOUS, Thiago Saddi. O art. 1.031 do Código Civil e sua interpretação. In: YARSHELL, Flávio Luiz; PEREIRA, Guilherme Setoguti (Coord.). Processo societário. São Paulo: Quartier Latin, 2015. v. 2.

YASBELL, Flávio Luiz; MATOS, Felipe do Amaral. O procedimento especial de dissolução (parcial) de sociedade no projeto de CPC. In: YARSHELL, Flávio Luiz; 
PEREIRA, Guilherme Setoguti (Coord.). Processo societário. São Paulo: Quartier Latin, 2012. 